Technical Note

\title{
Screening and Identification of Mitragynine and 7-Hydroxymitragynine in Human Urine by LC-MS/MS
}

\author{
Hanzhuo Fu *, Frank X. Cid, Nat Dworkin, James Cocores and Gloria Shore
}

Ultimate Analysis Laboratory, 108 NW 4th St, Boca Raton, FL 33432, USA

* Author to whom correspondence should be addressed; E-Mail: hanzhuo.fu@gmail.com.

Academic Editor: Frank L. Dorman

Received: 25 March 2015 / Accepted: 20 May 2015 / Published: 25 May 2015

\begin{abstract}
Kratom is a tree planted in Southeast Asia, including Thailand, Malaysia, Myanmar (Burma) and elsewhere in the region. A long history of usage and abuse of kratom has led to the classification of kratom as a controlled substance in its native Thailand and other Southeast Asian countries. However, kratom is not controlled in the United States, and the wide availability of kratom on the Internet and in the streets has led to its emergence as an herbal drug of misuse. With the increasing popularity of kratom, efficient protocols are needed to detect kratom use. In this study, a rapid method for the analysis of kratom compounds, mitragynine and 7-hydroxymitragynine, in human urine has been developed and validated using high-performance liquid chromatography-tandem mass spectrometry (LC-MS/MS). The chromatographic system employed a $2.6-\mu \mathrm{m} 100 \mathrm{~mm} \times 2.1 \mathrm{~mm}$ phenyl-hexyl analytical column and gradient elution with a $0.4-\mathrm{mL} / \mathrm{min}$ flow rate of water and acetonitrile as mobile phases. A triple quadrupole mass spectrometer was used as the detector for data acquisition. The analyst was the quantification software. The established method demonstrated linearity of $>0.99$ for both analytes, and low detection limits were obtained down to $0.002581 \mathrm{ng} / \mathrm{mL}$ for mitragynine and $0.06910 \mathrm{ng} / \mathrm{mL}$ for 7-hydroxymitragynine. The validated method has been utilized for clinical analysis of urine for the purpose of mitragynine and 7-hydroxymitragynine detection.
\end{abstract}

Keywords: mitragynine; 7-hydroxymitragynine; kratom; LC-MS/MS 


\section{Introduction}

Kratom has long been used by opioid-dependent individuals as an alternative to their unavailable opioid of choice and chronic pain medication, as a stealth-to-urine drug screening opiate substitute while in opioid recovery treatment and recreationally, alone or as a booster [1-3]. However, it has also been used to reduce opioid craving [4,5] and to treat opioid withdrawal [6,7]. Kratom is derived from the Mitragyna speciose Korth tree in Southeast Asia, and like oxycodone, it has rare paradoxical properties consisting of augmented focus, concentration and physical energy, with concurrent reduction in physical and emotional pain [8,9]. Kratom was federally outlawed in Thailand by 1950 and in 2003 by Malaysia [10,11]. The U.S. Drug Enforcement Administration (USDEA) Office of Diversion Control lists kratom as a drug of concern; however, kratom remains legal in the U.S. and is also one of the most popular legal highs in the U.K. [12-15]. M. speciose Korth contains more than 25 alkaloids that vary quantitatively depending on geographic location [5,10,16-18].

Mitragynine (Figure 1) is structurally similar to the aphrodisiac yohimbine, which is the most prevalent of these alkaloids, and mitragynine is believed to be responsible for kratom's opioid effects [19]. Although mitragynine is structurally distinct from morphine and codeine, it acts on a supraspinal mu- and delta-opioid receptor and serotonergic and noradrenergic pathways in the spinal cord [20]. Mitragynine is considerably more potent than morphine $[10,21,22]$ and is thought to act centrally on mu-opioid receptors within the nucleus accumbens to produce its addictive cycle of anhedonia followed by hedonia followed by anhedonia [23-27], the definition of progression, tolerance and addiction. Kratom products are available as leaves, gum and powder, and the alkaloid is usually brewed into tea or smoked [28-30]. The effects of kratom depend on the dose used, beginning within 5 to $10 \mathrm{~min}$ and lasting for about $1 \mathrm{~h}$ [31-34]. The kratom high varies and is dose dependent. Lower doses tend to yield a dopaminergic-dominant result or stimulation, while higher doses result in a mu-opioid receptor-dominant effect, which eclipses the dopaminergic expression or physical and emotional hedonia and pain relief $[12,24,35,36]$.

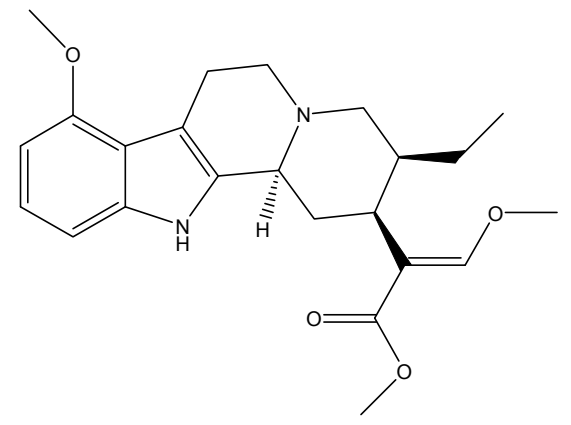

Mitragynine (MW 398.50) $\mathrm{C}_{23} \mathrm{H}_{30} \mathrm{~N}_{2} \mathrm{O}_{4}$

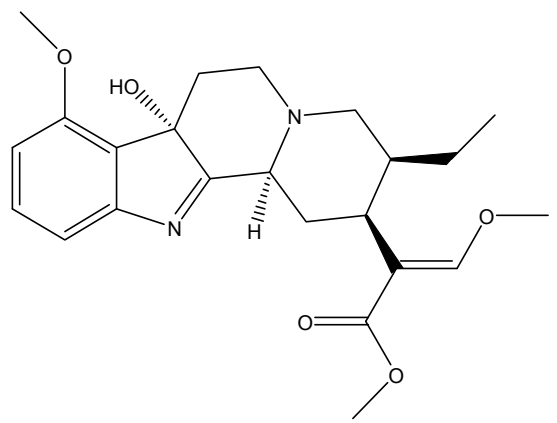

7-Hydroxymitragynine (MW 414.49)

$\mathrm{C}_{23} \mathrm{H}_{30} \mathrm{~N}_{2} \mathrm{O}_{5}$

Figure 1. Chemical structure of "kratom" compounds.

Many analytical approaches have been reported for the separation and identification of kratom, including GC and GC-MS [2,3,37-39], LC and LC-MS [38,40-44] and CE and CE-MS [43,45,46]. In this study, we report a rapid and effective method for quantification mitragynine and 7-hydroxymitragynine compounds in human urine matrix. Correlation coefficients greater than 0.99 were obtained for both analytes, and limits of detection down to $0.002581 \mathrm{ng} / \mathrm{mL}$ and $0.06910 \mathrm{ng} / \mathrm{mL}$ were achieved for mitragynine and 7-hydroxymitragynine, respectively. 


\section{Experimental Section}

\subsection{Chemicals and Materials}

Acetonitrile and HPLC-grade water are purchased from EMD Millipore (Billerica, MA, USA). Formic acid was purchased from Amresco (Solon, OH, USA). Mitragynine (Item Number M-152, Lot Number FN102312-03) and 7-hydroxymitragynine (Item Number H-099, Lot Number FN122812-01) standards were purchased from Cerilliant (Round Rock, TX, USA). Internal standards mitragynine-D3 (Item Number M-182, Lot Number FN06021404) and 7-hydroxymitragynine-D3 (Item Number H-109, Lot Number FN05291405) were purchased from Cerilliant (Round Rock, TX, USA). The phenyl-hexyl HPLC column was purchased from Phenomenex (Torrance, CA, USA).

\subsection{Instrumentation}

The assay was developed on a Shimadzu 20AD liquid chromatography (Columbia, MD, USA) coupled to an AB Sciex QTrap 5500 quadrupole linear ion trap mass spectrometer (Framingham, MA, USA). A $2.6-\mu \mathrm{m} 100 \mathrm{~mm} \times 2.1 \mathrm{~mm}$ phenyl-hexyl analytical column was employed, and gradient elution with a $0.4-\mathrm{mL} / \mathrm{min}$ flow rate of water and acetonitrile as mobile phases was utilized. The LC-MS/MS conditions were optimized to achieve rapid and effective goals for the detection of kratom compounds.

\subsection{Standard Solutions}

Calibration standard solutions were prepared weekly to keep the active component fresh. Methanol standards and urine standards were prepared for injection, respectively. The methanol standards were stored at $-8{ }^{\circ} \mathrm{C}$, and the urine standards were stored at $4{ }^{\circ} \mathrm{C}$. For HPLC injection, $50 \mu \mathrm{L}$ of working standards, $50 \mu \mathrm{L}$ of $10 \mathrm{ng} / \mathrm{mL}$ internal standards and $150 \mu \mathrm{L}$ of Mobile Phase A solution were mixed as the injection standards. For testing on urine samples, working standards were substituted with human urine.

\section{Results and Discussion}

\subsection{HPLC Conditions}

A phenyl-hexyl HPLC column was employed to develop the assay, as previous studies showed that the column had a wide range for $\mathrm{pH}$ suitability. In addition, the phenyl-hexyl column provides increased aromatic selectivity and increased hydrophobic retention. The phenyl phases tend to exhibit good shape selectivity, and with a controlled, low-level surface charge inherent to the particles in combination with a tri-functionally-bonded phenyl-hexyl ligand, the phenyl-hexyl column provides an exceptional peak shape for basic compounds, even in the ionized form under acidic mobile phase conditions. The column was maintained in an oven with $40^{\circ} \mathrm{C}$. Analytes were eluted with gradient mobile phases of water with $0.1 \%$ formic acid (Mobile Phase A (MPA)) and acetonitrile (Mobile Phase B (MPB)). Formic acid is a commonly-used additive for reversed-phase liquid chromatography, as it provides protons and promotes ionization for analytes. Acetonitrile is an organic solvent that provides advantages over methanol in terms of low back pressure, high sensitivity and less ghost peak for the gradient elution program. 
The gradient elution starts with 5\% MPB, with a linear gradient to $75 \%$ within 3 min, followed by a 3 -min stabilization. Then, the percentage of MPB drops to $20 \%$ for post-run equilibrium. The optimized separation results are presented as Figure 2.

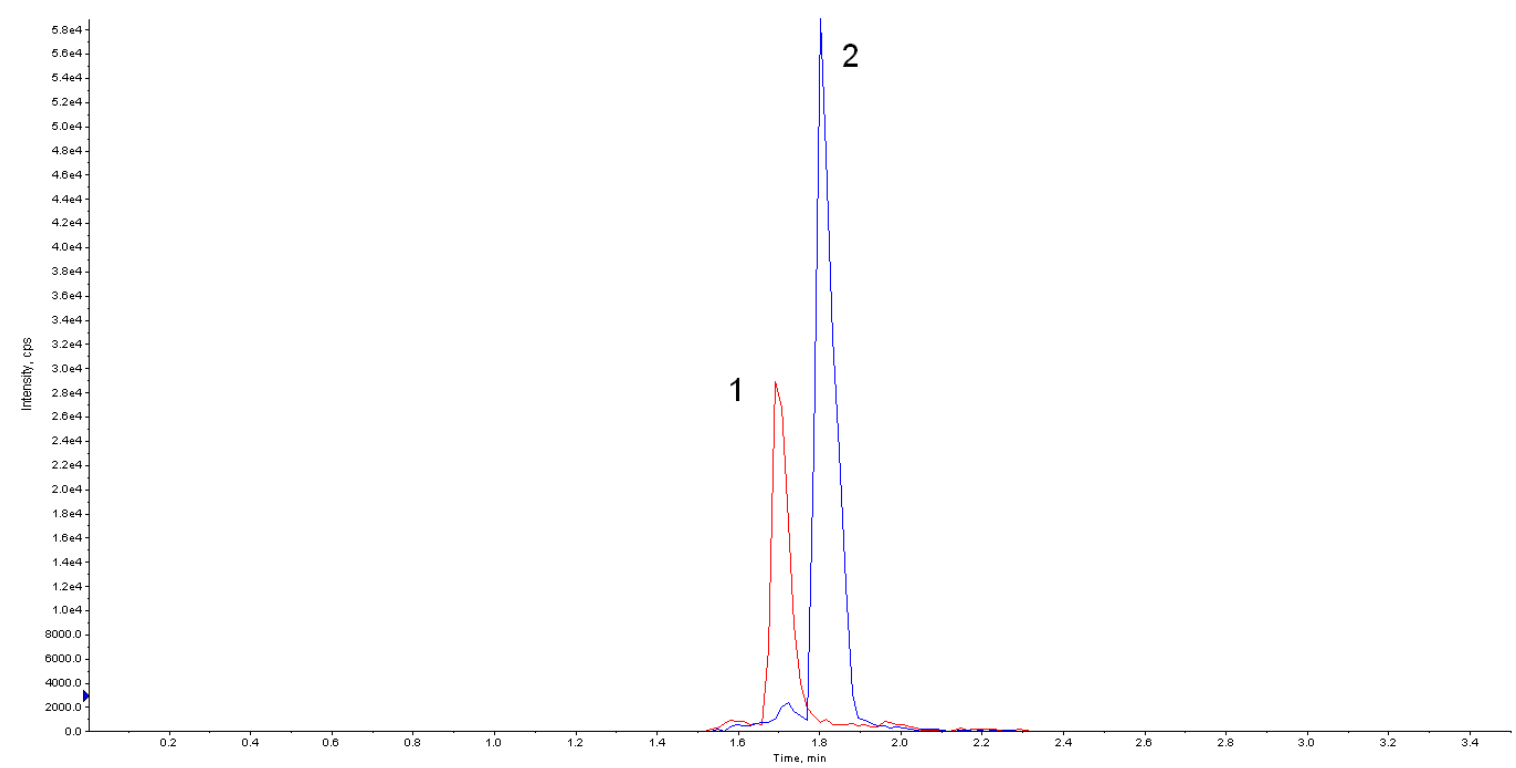

Figure 2. The extracted ion chromatogram of kratom. The major components of kratom, mitragynine and its major metabolite, 7-OH-mitragynine, are shown. Peak identification: (1) 7-hydroxymitragynine; (2) mitragynine. Concentration: $5 \mathrm{ng} / \mathrm{mL}$ for both compounds.

\subsection{Mass Spectrometry Parameters}

Before connecting to LC, the direct infusion experiments were carried out for exploring optimum mass spectrometry conditions. Different parameters, such as ion spray voltage, ionization temperature, were explored. The optimum mass spectrometer conditions are demonstrated as Table 1.

Table 1. Mass spectrometer conditions.

\begin{tabular}{cc}
\hline Ion Spray Voltage & $2500 \mathrm{~V}$ \\
Temperature & $600^{\circ} \mathrm{C}$ \\
Collision Gas & Medium \\
Ion Source Gas 1 & 50.0 \\
Ion Source Gas 2 & 70.0 \\
\hline
\end{tabular}

After mass spectrometer conditions finalized, multiple reaction monitoring (MRM) parameters were determined. For drug analytes, two transitions were tracked. For the internal standards, one transition was monitored. The values are presented in Table 2.

Table 2. MRM parameters for analytes and internal standards.

\begin{tabular}{cccc}
\hline Compound & Precursor ion (m/z) & Product ion (m/z) & Collision energy (volts) \\
\hline Mitragynine & 399.3 & $174.1 / 159.0$ & $40 / 55$ \\
Mitragynine-D3 & 402.3 & 238.1 & 30 \\
7-Hydroxymitragynine & 415.3 & $190.0 / 238.1$ & $40 / 27$ \\
7-Hydroxymitragynine-D3 & 418.3 & 193.1 & 40 \\
\hline
\end{tabular}




\subsection{Method Validation}

Once the assay was developed, we proceeded to the validation steps. Validation is a vital part before an assay can be applied to routine testing. Several parameters were studied as the parts of the validation process.

\subsubsection{Linearity}

Six concentration levels $(2,3.75,5,15,25$ and $50 \mathrm{ng} / \mathrm{mL})$ with six replicates of each level were used for establishing the regression model.

For mitragynine, the accuracy of the concentrations of analytes at all levels is within $\pm 10 \%$ of the expected value, except at the lower limit of quantification $(0.08 \mathrm{ng} / \mathrm{mL})$, where concentrations are within $\pm 15 \%$ of the expected values. These data qualify for the requirement of the validation plan, which asks for an accuracy within $100 \% \pm 25 \%$. The percent of the relative standard deviation $(\% \mathrm{RSD}$, or percent of the coefficient of variation, $\% \mathrm{CV}$ ) is below $10 \%$ at all concentration levels, which qualifies for the requirement of the validation plan (less than $25 \% \mathrm{CV}$ ). The coefficient of determination $\left(\mathrm{R}^{2}\right)$ is 0.9941 for mitragynine. This demonstrates that the calibration model of mitragynine is close to linear $(=1)$ and is valid for quantification.

For 7-hydroxymitragynine, the accuracy of the concentrations of analytes at all levels is within $\pm 10 \%$ of the expected value. These data qualify the requirement of the validation plan, which asks for accuracy within $100 \% \pm 25 \%$. The percent of the relative standard deviation $(\% \mathrm{RSD}$, or percent of the coefficient of variation, $\% \mathrm{CV}$ ) is below $10 \%$ at all concentration levels, which qualifies the requirement of the validation plan (less than $25 \% \mathrm{CV}$ ). The coefficient of determination $\left(\mathrm{R}^{2}\right)$ is 0.9951 for 7-hydroxymitragynine. This demonstrates that the calibration model of 7-hydroxymitragynine is close to linear (=1) and is valid for quantification.

\subsubsection{Carryover}

Carryover is measured by evaluating blank urine samples injected after the highest concentration samples in the calibration curve.

For mitragynine and 7-hydroxymitragynine, the back-calculated concentration of the blank sample was " $0 \mathrm{ng} / \mathrm{mL}$ ", which means the carryover condition of the system is acceptable.

\subsubsection{Sensitivity}

Sensitivity is measured as the limit of detection (LOD) and the limit of quantification (LOQ). Four concentration levels, $0.01,0.02,0.04$ and $0.08 \mathrm{ng} / \mathrm{mL}$, were used to determine LOD and LOQ. Three calibration curves with duplicate injections at four levels were performed.

To calculate LOD and LOQ, the standard deviation of the three y-intercepts (SDYint) is first calculated along with the mean of the three slopes (means). The LOD equals $\left(3.3 \times \mathrm{SD}_{\text {Yint }}\right) / \mathrm{means}_{\mathrm{s}}$, and the LOQ equals $(10 \times \mathrm{SD}$ Yint $) /$ means.

For mitragynine, LOD down to $0.002581 \mathrm{ng} / \mathrm{mL}$ and LOD down to $0.007821 \mathrm{ng} / \mathrm{mL}$ were obtained. These data demonstrate that the method is very sensitive for both qualification and quantification for mitragynine. 
For 7-hydroxymitragynine, LOD down to $0.06910 \mathrm{ng} / \mathrm{mL}$ and LOD down to $0.2094 \mathrm{ng} / \mathrm{mL}$ were obtained. These data demonstrate that the method is very sensitive for both qualification and quantification for 7-hydroxymitragynine.

\subsubsection{Precision}

Precision is measured by analyzing two concentrations (here, low QC and high QC) in duplicates of analytes for total ten batches. It is recommended to analyze two batches per day for five days; or this can be done for one day per batch. However, no more than two batches per day is allowed, and a minimum of $2 \mathrm{~h}$ between batches should be assessed. In this way, within-day (intraday) and day-to-day (interday) precision will be evaluated.

Here, precision data from the following batches, ten batches in total, are presented.

For both mitragynine and 7-hydroxymitragynine, $\% \mathrm{CV}$ at all concentration levels is less than $15 \%$, which meets the requirement $(<25 \%)$.

\subsubsection{Stability}

Stability is measured by analyzing two concentrations (here, low QC and high QC) of analytes. We analyze the samples to establish time zero $\left(\mathrm{T}_{0}\right)$, then after a certain time span $\left(\mathrm{T}_{\mathrm{x}}\right)$, samples are re-analyzed. Results will be compared between $\mathrm{T}_{0}$ and $\mathrm{T}_{\mathrm{x}}$.

\subsubsection{Short-Term Stability (Autosampler Stability)}

Autosampler stability was evaluated for a 92-h time span. This simulates the situation in which samples were prepared on Friday, being processed during the weekend, and then data collected on Monday morning.

For both mitragynine and 7-hydroxymitragynine, $T_{x}$ concentrations $(x=92 h)$ at all concentration levels are within $\pm 0.3 \%$ of $\mathrm{T}_{0}$, which meets the requirement ( $\mathrm{T}_{\mathrm{x}}$ within $\pm 25 \%$ of $\mathrm{T}_{0}$ ). The data of the short-term stability study are presented as Table 3.

Table 3. Data of the short-term stability study for a period of 92 hours $(n=3)$.

\begin{tabular}{c|cc|cc}
\hline & \multicolumn{2}{|c|}{ Mitragynine } & \multicolumn{2}{c}{ 7-hydroxymitragynine } \\
\hline & Low QC & High QC & Low QC & High QC \\
$\mathrm{T}_{0}$ & $0.1502 \mathrm{ng} / \mathrm{mL}$ & $1.0000 \mathrm{ng} / \mathrm{mL}$ & $0.7502 \mathrm{ng} / \mathrm{mL}$ & $4.9983 \mathrm{ng} / \mathrm{mL}$ \\
$\mathrm{T}_{\mathrm{x}}$ & $0.1498 \mathrm{ng} / \mathrm{mL}$ & $0.9997 \mathrm{ng} / \mathrm{mL}$ & $0.7502 \mathrm{ng} / \mathrm{mL}$ & $5.0000 \mathrm{ng} / \mathrm{mL}$ \\
\% Difference & $0.266 \%$ & $0.03 \%$ & $0 \%$ & $-0.034 \%$ \\
\hline
\end{tabular}

\subsubsection{Long-Term Stability (Storage Stability)}

Storage stability, in Ultimate Analysis Laboratory, refers to specimen storage for two weeks in the fridge after the initial received date. Hence, storage stability was evaluated for a two-week time span.

For both mitragynine and 7-hydroxymitragynine, $\mathrm{T}_{\mathrm{x}}$ concentrations $(\mathrm{x}=2$ weeks $)$ at all concentration levels were within $\pm 0.3 \%$ of $T_{0}$, which meets the requirement $\left(T_{x}\right.$ within $\pm 25 \%$ of $\left.T_{0}\right)$. The data of the long-term stability study are presented as Table 4. 
Table 4. Data of the long-term stability study for a period of 14 days $(n=3)$.

\begin{tabular}{c|cc|cc}
\hline & \multicolumn{2}{|c|}{ Mitragynine } & \multicolumn{2}{c}{ 7-hydroxymitragynine } \\
\hline & Low QC & High QC & Low QC & High QC \\
$\mathrm{T}_{0}$ & $0.1500 \mathrm{ng} / \mathrm{mL}$ & $1.0017 \mathrm{ng} / \mathrm{mL}$ & $0.7500 \mathrm{ng} / \mathrm{mL}$ & $4.9967 \mathrm{ng} / \mathrm{mL}$ \\
$\mathrm{T}_{\mathrm{x}}$ & $0.1503 \mathrm{ng} / \mathrm{mL}$ & $0.9990 \mathrm{ng} / \mathrm{mL}$ & $0.7500 \mathrm{ng} / \mathrm{mL}$ & $5.0000 \mathrm{ng} / \mathrm{mL}$ \\
$\%$ Difference & $-0.20 \%$ & $0.27 \%$ & $0 \%$ & $-0.066 \%$ \\
\hline
\end{tabular}

\subsubsection{Matrix Effect Study}

The matrix effect is a type of assay interference caused by ion suppression or ion enhancement in the matrix. To test for the matrix effect, five injections of the standards were made, and the results were compared with the "complicated matrix", which in the authors' case, were human urine samples. The \% differences between the standards and the urine samples are calculated. The results obtained were 35\%, which qualifies for the requirement of the validation plan $(40 \%)$.

\subsection{Capability of the Established Method}

After the method was developed and validated, spiked urine samples were utilized to examine the capability of the method. Different concentration levels of standard drugs were spiked into synthetic urine to prepare run solutions $(0,5,25,50,100 \mathrm{ng} / \mathrm{mL})$. The results demonstrated that the recovery efficiency of both analytes was above $95 \%$.

An unknown sample was examined using the established method and the extracted ion chromatogram is shown as Figure 3. The results were $51.25 \mathrm{ng} / \mathrm{mL}$ of mitragynine and $8.72 \mathrm{ng} / \mathrm{mL}$ of 7-hydroxymitragynine. These numbers exceed our cut-off values, which indicates that the sample was positive for both mitragynine and 7-hydroxymitragynine. Two quality control (QC) standards of $3.5 \mathrm{ng} / \mathrm{mL}$ and $25 \mathrm{ng} / \mathrm{mL}$ were utilized to monitor the data consistence and instrument performance. Table 5 shows the performance of the QCs.

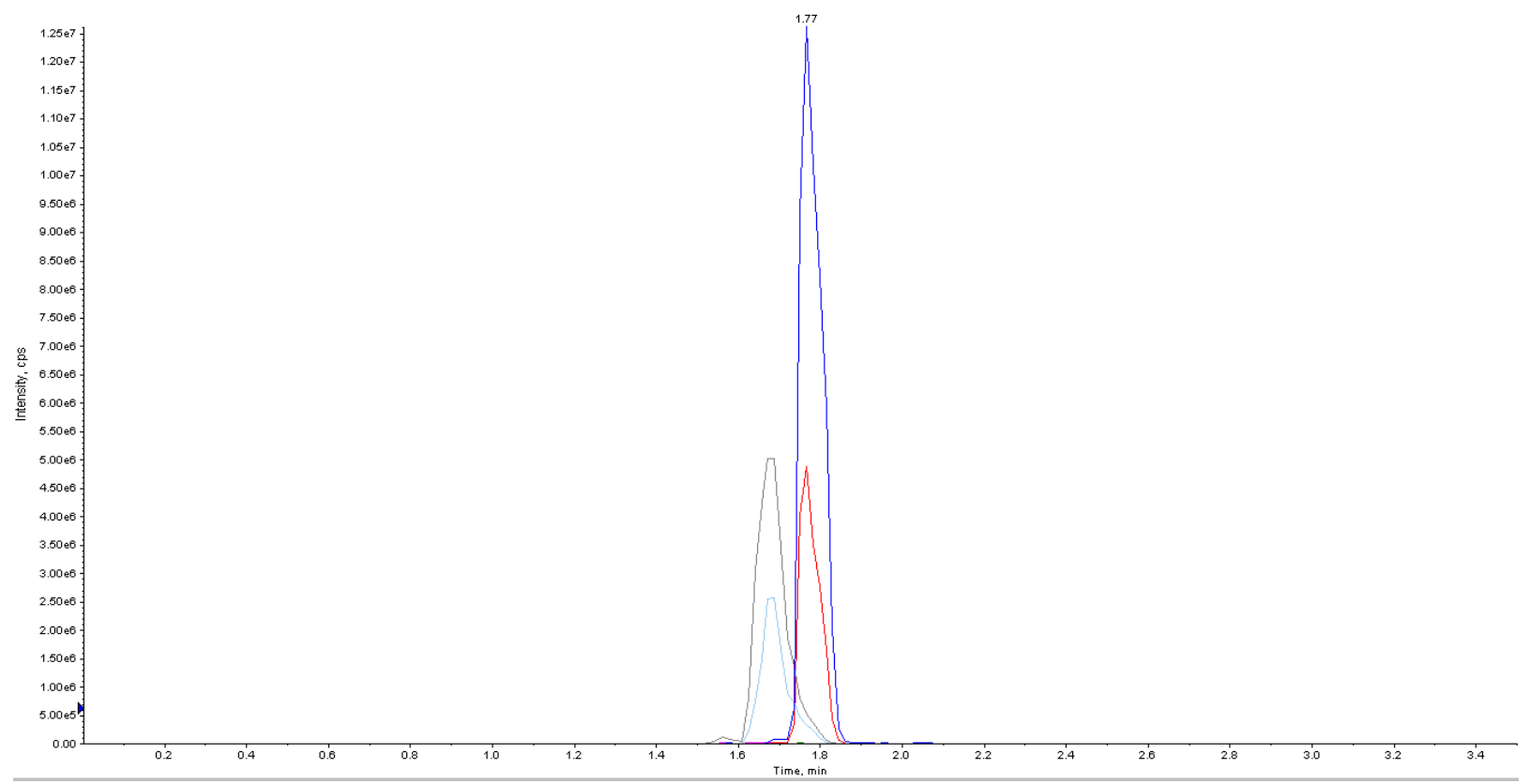

Figure 3. Extracted Ion Chromatogram of an unknown sample. 
Table 5. QC summary for daily analysis of mitragynine and 7-hydroxymitragynine (29 Jan 2015).

\begin{tabular}{|c|c|c|c|c|c|}
\hline $\begin{array}{l}\text { Analyte Peak Name } \\
\text { (MRM Transition) }\end{array}$ & $\begin{array}{c}\text { Mean Calculated } \\
\text { Concentration } \\
(\mathrm{ng} / \mathrm{mL}) \\
\end{array}$ & $\begin{array}{c}\text { Std. } \\
\text { Deviation } \\
(\mathrm{ng} / \mathrm{mL})\end{array}$ & $\% \mathrm{CV}$ & $\begin{array}{c}\text { Number of } \\
\text { Values Used }\end{array}$ & $\begin{array}{c}\text { Mean } \\
\text { Accuracy (\%) }\end{array}$ \\
\hline $\begin{array}{c}\text { Mitragynine1 } \\
(399.300 / 174.100 \mathrm{Da})\end{array}$ & 3.594 & 0.004 & 0.12 & 2 & 95.84 \\
\hline $\begin{array}{c}\text { Mitragynine } 2 \\
(399.300 / 159.000 \mathrm{Da})\end{array}$ & 3.398 & 0.057 & 1.69 & 2 & 90.60 \\
\hline $\begin{array}{c}\text { 7-hydroxymitragynine } 1 \\
\text { (415.300/190.000 Da) }\end{array}$ & 3.884 & 0.048 & 1.24 & 2 & 103.57 \\
\hline $\begin{array}{c}\text { 7-hydroxymitragynine } 2 \\
(415.300 / 238.100 \mathrm{Da})\end{array}$ & 3.516 & 0.059 & 1.69 & 2 & 93.75 \\
\hline $\begin{array}{c}\text { mitragynine } 1 \\
(399.300 / 174.100 \mathrm{Da})\end{array}$ & 24.616 & 0.353 & 1.44 & 2 & 98.46 \\
\hline $\begin{array}{c}\text { mitragynine } 2 \\
(399.300 / 159.000 \mathrm{Da})\end{array}$ & 23.915 & 0.282 & 1.18 & 2 & 95.66 \\
\hline $\begin{array}{c}\text { 7-hydroxymitragynine } 1 \\
(415.300 / 190.000 \mathrm{Da})\end{array}$ & 24.844 & 0.107 & 0.43 & 2 & 99.37 \\
\hline $\begin{array}{l}\text { 7-hydroxymitragynine } 2 \\
(415.300 / 238.100 \mathrm{Da})\end{array}$ & 27.241 & 0.678 & 2.49 & 2 & 108.96 \\
\hline
\end{tabular}

\section{Conclusions}

In this study, a specific and selective LC-MS/MS method has been developed for detecting the use of mitragynine and 7-hydroxymitragynine in urine samples. The procedure utilizes a quantitative MRM procedure for the detection of both analytes. The assay has been validated and can be used for routine drug testing of both drugs. Overall, the assay exhibits a rapid and efficient means for the identification of kratom-related compounds in human urine.

\section{Acknowledgements}

The authors acknowledge Mesut Kosker of Ultimate Analysis Laboratory and Anton Lopze of Zef Scientific for technical support on the LC-MS/MS system. The authors would like to thank all other employees at Ultimate Analysis Laboratory for assistance and support on the project.

\section{Author Contributions}

Hanzhuo Fu: designed and performed the experiment, did the data analysis, manuscript writing and revision. Frank X. Cid: laboratory and instrument support, project design and supervision, as well as manuscript revision. Nat Dworkin: project design and supervision, as well as manuscript revision. James Cocores: manuscript Introduction preparation, critical reading and manuscript revision. Gloria Shore: critical reading and manuscript revision. All authors read and approved the final manuscript.

\section{Conflicts of Interest}

The authors declare no conflict of interest. 


\section{References}

1. Ward, J.; Rosenbaum, C.; Hernon, C.; McCurdy, C.; Boyer, E. Herbal medicines for the management of opioid addiction. CNS Drugs 2011, 25, 999-1007.

2. Le, D.; Goggin, M.M.; Janis, G.C. Analysis of mitragynine and metabolites in human urine for detecting the use of the psychoactive plant kratom. J. Anal. Toxicol. 2012, doi:10.1093/jat/bks073.

3. Rosenbaum, C.; Carreiro, S.; Babu, K. Here today, gone tomorrow... and back again? A review of herbal marijuana alternatives ( $k 2$, spice), synthetic cathinones (bath salts), kratom, salvia divinorum, methoxetamine, and piperazines. J. Med. Toxicol. 2012, 8, 15-32.

4. Assanangkornchai, S.; Muekthong, A.; Sam-angsri, N.; Pattanasattayawong, U. The use of mitragynine speciosa ("krathom"), an addictive plant, in thailand. Subst. Use Misuse 2007, 42, 2145-2157.

5. Arndt, T.; Claussen, U.; Güssregen, B.; Schröfel, S.; Stürzer, B.; Werle, A.; Wolf, G. Kratom alkaloids and o-desmethyltramadol in urine of a "krypton" herbal mixture consumer. Forensic Sci. Int. 2011, 208, 47-52.

6. Harizal, S.N.; Mansor, S.M.; Hasnan, J.; Tharakan, J.K.J.; Abdullah, J. Acute toxicity study of the standardized methanolic extract of mitragyna speciosa korth in rodent. J. Ethnopharm. 2010, 131, 404-409.

7. Kumarnsit, E.; Keawpradub, N.; Nuankaew, W. Effect of mitragyna speciosa aqueous extract on ethanol withdrawal symptoms in mice. Fitoterapia 2007, 78, 182-185.

8. Holler, J.M.; Vorce, S.P.; McDonough-Bender, P.C.; Magluilo, J.; Solomon, C.J.; Levine, B. A drug toxicity death involving propylhexedrine and mitragynine. J. Anal. Toxicol. 2011, 35, 54-59.

9. Kronstrand, R.; Roman, M.; Thelander, G.; Eriksson, A. Unintentional fatal intoxications with mitragynine and o-desmethyltramadol from the herbal blend krypton. J. Anal. Toxicol. 2011, 35, 242-247.

10. Vicknasingam, B.; Narayanan, S.; Beng, G.T.; Mansor, S.M. The informal use of ketum (mitragyna speciosa) for opioid withdrawal in the northern states of peninsular malaysia and implications for drug substitution therapy. Int. J. Drug Policy 2010, 21, 283-288.

11. Jansen, K.L.R.; Prast, C.J. Psychoactive properties of mitragynine (kratom). J. Psychoact. Drugs 1988, 20, 455-457.

12. Babu, K.M.; McCurdy, C.R.; Boyer, E.W. Opioid receptors and legal highs: Salvia divinorum and kratom. Clin. Toxicol. 2008, 46, 146-152.

13. Schmidt, M.M.; Sharma, A.; Schifano, F.; Feinmann, C. "Legal highs" on the net-Evaluation of uk-based websites, products and product information. Forensic Sci. Int. 2011, 206, 92-97.

14. Boyer, E.W.; Babu, K.M.; Macalino, G.E.; Compton, W. Self-treatment of opioid withdrawal with a dietary supplement, kratom. Am. J. Addict. 2007, 16, 352-356.

15. Boyer, E.W.; Babu, K.M.; Adkins, J.E.; McCurdy, C.R.; Halpern, J.H. Self-treatment of opioid withdrawal using kratom (mitragynia speciosa korth). Addiction 2008, 103, 1048-1050.

16. Phongprueksapattana, S.; Putalun, W.; Keawpradub, N.; Wungsintaweekul, J. Mitragyna speciosa: Hairy root culture for triterpenoid production and high yield of mitragynine by regenerated plants. Zeitschrift für Naturforschung. C 2008, 63, 691-698. 
17. Zhao, C.; Pelaez, M.; Dionysiou, D.D.; Pillai, S.C.; Byrne, J.A.; O'Shea, K.E. Uv and visible light activated tio2 photocatalysis of 6-hydroxymethyl uracil, a model compound for the potent cyanotoxin cylindrospermopsin. Catal. Today 2014, 224, 70-76.

18. O'Shea, K.; Zhao, C.; Dionysiou, D.D.; Pelaez, M.; Song, W.; Byrne, J.A.; Pillai, S.C. Advanced Oxidation of Cylindrospermopsin (Cyanobacterial Toxin): Mechanistic and Practical Considerations. In Abstracts of Papers of the American Chemical Society; American Chemical Society: Washington, DC, USA, 2013.

19. Kong, W.M.; Chik, Z.; Ramachandra, M.; Subramaniam, U.; Aziddin, R.E.R.; Mohamed, Z. Evaluation of the effects of mitragyna speciosa alkaloid extract on cytochrome p450 enzymes using a high throughput assay. Molecules 2011, 16, 7344-7356.

20. Matsumoto, K.; Mizowaki, M.; Suchitra, T.; Takayama, H.; Sakai, S.-I.; Aimi, N.; Watanabe, H. Antinociceptive action of mitragynine in mice: Evidence for the involvement of supraspinal opioid receptors. Life Sci. 1996, 59, 1149-1155.

21. de la Cruz, A.A.; Hiskia, A.; Kaloudis, T.; Chernoff, N.; Hill, D.; Antoniou, M.G.; He, X.; Loftin, K.; O'Shea, K.; Zhao, C.; et al. A review on cylindrospermopsin: The global occurrence, detection, toxicity and degradation of a potent cyanotoxin. Environ. Sci. 2013, 15, 1979-2003.

22. Luzi, M.; Zhao, C.; O'Shea, K. Synthesis and Oxidative Degradation 6-(Hydroxymethyl) Uracil as a Model Compound for Cylindrospermopsin (cyn), A Potent Cyanotoxin. In Abstracts of Papers of the American Chemical Society; American Chemical Society: Washington, DC, USA, 2013.

23. Stolt, A.-C.; Schröder, H.; Neurath, H.; Grecksch, G.; Höllt, V.; Meyer, M.; Maurer, H.; Ziebolz, N.; Havemann-Reinecke, U.; Becker, A. Behavioral and neurochemical characterization of kratom (mitragyna speciosa) extract. Psychopharmacology 2014, 231, 13-25.

24. Cocores, J.A.; Gold, M.S. The salted food addiction hypothesis may explain overeating and the obesity epidemic. Med. Hypotheses 2009, 73, 892-899.

25. Merola, G.; Fu, H.; Tagliaro, F.; Macchia, T.; McCord, B.R. Chiral separation of 12 cathinone analogs by cyclodextrin-assisted capillary electrophoresis with uv and mass spectrometry detection. Electrophoresis 2014, 35, 3231-3241.

26. Zhao, C.; Arroyo-Mora, L.E.; DeCaprio, A.P.; Sharma, V.K.; Dionysiou, D.D.; O'Shea, K.E. Reductive and oxidative degradation of iopamidol, iodinated $\mathrm{x}$-ray contrast media, by fe(iii)-oxalate under uv and visible light treatment. Water Res. 2014, 67, 144-153.

27. Zhao, C.; Arroyo-Mora, L.E.; DeCaprio, A.P.; Dionysiou, D.D.; O’Shea, K.E. Photodegradation of Iodinated X-ray Contrast Media Iopamidol by fe(iii)-oxalate System with the Composition of h2o2. In Abstracts of Papers of the American Chemical Society; American Chemical Society:Washington, DC, USA, 2014.

28. Maruyama, T.; Kawamura, M.; Kikura-Hanajiri, R.; Takayama, H.; Goda, Y. The botanical origin of kratom (mitragyna speciosa; rubiaceae) available as abused drugs in the japanese markets. J. Nat. Med. 2009, 63, 340-344.

29. Chen, L.; Zhao, C.; Dionysiou, D.D.; O'Shea, K.E. TiO2 photocatalytic degradation and detoxification of cylindrospermopsin. J. Photochem. Photobiol. A 2015, 307-308, 115-122.

30. Chittrakarn, S.; Keawpradub, N.; Sawangjaroen, K.; Kansenalak, S.; Janchawee, B. The neuromuscular blockade produced by pure alkaloid, mitragynine and methanol extract of kratom leaves (mitragyna speciosa korth.). J. Ethnopharm. 2010, 129, 344-349. 
31. Suwanlert, S. A study of kratom eaters in thailand. Bull. Narcotics 1975, 27, 21-27.

32. Zhao, C.; Sharma, V.; Dionysiou, D.; O'Shea, K. Oxidation of Cylindrospermopsin and Its Model Compound 6-Hydroxymethyl Uracil by Ferrate (vi). In Abstracts of Papers of the American Chemical Society; American Chemical Society:Washington, DC, USA, 2014.

33. Zhao, C.; Pelaez, M.; Dionysiou, D.D.; Pillai, S.C.; Byrne, J.A.; O'Shea, K. Visible Light Activated (vla) tio2 Photocatalysis of 6-Hydroxymethyl Uracil as a Model Compound for the Cylindrospermopsin. In Abstracts of Papers of the American Chemical Society; American Chemical Society: Washington, DC, USA, 2013.

34. Fan, M.; Yang, D.; Wang, X.; Liu, W.; Fu, H. Doss-based qails: As both neat lubricants and lubricant additives with excellent tribological properties and good detergency. Ind. Eng. Chem. Res. 2014, 53, 17952-17960.

35. Liu, S.; Zhao, Y.; Hu, X.; O'Shea, K.; Ma, L.; Zhao, C.; Ma, F.; Wu, M. Control of microcystis aeruginosa growth and the associated microcystin cyanotoxin remediation by electron beam irradiation (ebi). RSC Adv. 2015, 5, 31292-31297.

36. Yang, D.; Li, Z.; Diwu, Y.A.; Fu, H.; Liao, J.; Wei, C.; Diwu, Z. A novel fluorogenic coumarin substrate for monitoring acid phosphatase activity at low ph environment. Curr. Chem. Genom. 2008, 2, 48-50.

37. Philipp, A.; Meyer, M.; Wissenbach, D.; Weber, A.; Zoerntlein, S.; Zweipfenning, P.M.; Maurer, H. Monitoring of kratom or krypton intake in urine using gc-ms in clinical and forensic toxicology. Anal. Bioanal. Chem. 2011, 400, 127-135.

38. Meyer, G.M.J.; Meyer, M.R.; Wissenbach, D.K.; Maurer, H.H. Studies on the metabolism and toxicological detection of glaucine, an isoquinoline alkaloid from glaucium flavum (papaveraceae), in rat urine using gc-ms, lc-msn and lc-high-resolution msn. J. Mass Spectrom. 2013, 48, 24-41.

39. Kapp, F.; Maurer, H.; Auwärter, V.; Winkelmann, M.; Hermanns-Clausen, M. Intrahepatic cholestasis following abuse of powdered kratom (mitragyna speciosa). J. Med. Toxicol. 2011, 7, 227-231.

40. Kikura-Hanajiri, R.; Kawamura, M.; Maruyama, T.; Kitajima, M.; Takayama, H.; Goda, Y. Simultaneous analysis of mitragynine, 7-hydroxymitragynine, and other alkaloids in the psychotropic plant "kratom" (mitragyna speciosa) by lc-esi-ms. Forensic Toxicol. 2009, 27, 67-74.

41. Philipp, A.A.; Wissenbach, D.K.; Zoerntlein, S.W.; Klein, O.N.; Kanogsunthornrat, J.; Maurer, H.H. Studies on the metabolism of mitragynine, the main alkaloid of the herbal drug kratom, in rat and human urine using liquid chromatography-linear ion trap mass spectrometry. J. Mass Spectrom. 2009, 44, 1249-1261.

42. de Moraes, N.V.; Moretti, R.A.C.; Furr Iii, E.B.; McCurdy, C.R.; Lanchote, V.L. Determination of mitragynine in rat plasma by lc-ms/ms: Application to pharmacokinetics. J. Chromatogr. B 2009, $877,2593-2597$.

43. Posch, T.N.; Müller, A.; Schulz, W.; Pütz, M.; Huhn, C. Implementation of a design of experiments to study the influence of the background electrolyte on separation and detection in non-aqueous capillary electrophoresis-mass spectrometry. Electrophoresis 2012, 33, 583-598.

44. Al-Saffar, Y.; Stephanson, N.N.; Beck, O. Multicomponent lc-ms/ms screening method for detection of new psychoactive drugs, legal highs, in urine-experience from the swedish population. J. Chromatogr. B 2013, 930, 112-120. 
45. Fu, H.; McCord, B.R. Separation and Identification of Select Drugs by Monolith Capillary Electrochromatography. In Abstracts of Papers of the American Chemical Society; American Chemical Society:Washington, DC, USA, 2013.

46. Fu, H. Development of advanced capillary electrophoresis techniques with uv and mass spectrometry detection for forensic, pharmaceutical and environmental applications. 2014, paper 1531.

(C) 2015 by the authors; licensee MDPI, Basel, Switzerland. This article is an open access article distributed under the terms and conditions of the Creative Commons Attribution license (http://creativecommons.org/licenses/by/4.0/). 